\title{
PENERAPAN METODE BAYES DALAM PREDIKSI SEGEMENTASI PASAR PENJUALAN SMARTPHONE
}

\author{
Ahmad Zaki \\ Mahasiswa Jurusan Teknik Informatika STMIK Dharma Wacana Metro \\ Jalan Kenanga No.3, Mulyojati 16C, Metro Barat, Kota Metro, Lampung \\ Princez4k1@gmail.com
}

\begin{abstract}
Abstrak
Smartphone merupakan salah satu perangkat telekomunikasi yang memiliki banyak sekali manfaat yang besar dalam kehidupan sehari hari. Hampir di setiap daerah terdapat toko yang menjual smartphone, setiap toko mencoba melakukan inovasi yang lebih baik terhadap produk yang dijual dengan menyesuaikan terhadap aspek geografis bisnis serta demografis agar produk yang ditawarkan bisa bertahan dan bersaing dengan toko lain yang sejenis. Sistem Pakar adalah suatu program komputer yang dirancang untuk mengambil keputusan seperti keputusan yang diambil oleh seseorang atau beberapa orang pakar. Menurut Marimin (1992), Sistem Pakar adalah sistem perangkat lunak komputer yang menggunakan ilmu, fakta dan teknik berpikir dalam pengambilan keputusan untuk menyelesaikan masalah-masalah yang biasanya hanya dapat diselesaikan oleh tenaga ahli dalam bidang yang bersangkutan. Adapun tujuan yang akan dicapai adalah untuk membuat aplikasi sistem pakar yang berguna sebagai alat bantu untuk mendapatkan informasi dalam segementasi pasar penjualan smartphone. Hasil dalam penelitian ini adalah sistem pakar untuk menentukan segmentasi pasar penjualan smartphone di suatu daerah berdasarkan aspek geografi bisnis dan demografi dengan metode bayes yang memberikan nilai probabilitas pada produk smartphone.
\end{abstract}

Keyword: Smartphone, Sistem Pakar, Metode Bayes

\section{PENDAHULUAN}

\subsection{Latar Belakang}

Smartphone merupakan perangkat elektronik yang di sudah menjadi kebutuhan yang fital bagi kehidupan manusia.Di Indonesia pengguna smartphone aktif diperkirakan berjulah sekitar 250.100.000 orang, berkembang pesat hanya dalam kurun waktu tiga tahun (sumber: veba.com). Adapun dilansir oleh analisis kawakan Horace H.Dediu melalui blognya, asymco.com mengatakan bahwa Indonesia menempati posisi ke 5 besar delam pengguna aktif 47 juta, atau sekitas $14 \%$ dari seluruh toal pengguna ponsel (sumber: detik.com). smartphone dapat digunakan untuk mengakses internet dengan berbagai pilihan web browser yang tersedia juga memiliki software aplikasi yang dapat diunduh dengan mudah.
Pada saat inilah diperlukan strategi pemasaran yang tepat diantaranya untuk menentukan segmentasi pasar dalam penjualan smartphone.Menurut J. Paul Peter dan Jerry. C olson dalam bukunya Consumer Behavior ( 2000: 135 ) Segmentasi pasar sebagai proses memilah suatu pasar menjadi group-group yang berisikan konsumen sejenis dan memilih group dan individu yang paling tepat untuk dilayani perusahaan. Tujuan dari segmentasi pasar adalah mendesain produk-produk yang lebih responsif terhadap kebutuhan pasar, membantu pemasar mendeteksi siapa saja yang akan memakai pasar produknya, menemukan peluang, menguasai posisi superior yang kompetitif dan dapat menentukan strategi komunikasi yang efektif dan efisien. 
Sistem pakar (expert system) adalah sistem yang berusaha mengadopsi pengetahuan manusia ke komputer, agar komputer dapat menyelesaikan masalah seperti yang biasa dilakukan oleh para ahli. Sistem pakar yang baik dirancang agar dapat menyelesaikan suatu permasalahan tertentu dengan meniru kerja dari para ahli. Dengan sistem pakar ini, orang awampun dapat menyelesaikan masalah yang cukup rumit yang sebenarnya hanya dapat diselesaikan dengan bantuan para ahli. Didalam aplikasi tersebut diperlukan adanya metode yang dapat melakukan prediksi segementasi pasar smartphone dan mengambil keputusan dari pengetahuan awal yang diperlukan.

\section{LANDASAN TEORI}

\subsection{Kecerdasaran Buatan}

Kecerdasan buatan berasal dari bahasa Inggris "Artificial Intelligence" atau disingkat AI, yaitu Intelligence adalah kata sifat yang berarti cerdas, sedangkan Artificial artinya buatan. Kecerdasan buatan yang dimaksud adalah di sini merujuk pada mesin yang mampu berpikir, menimbang tindakan yang akan diambil, dan mampu mengambil keputusan seperti yang dilakukan oleh manusia. Berikut adalah beberapa defenisi kecerdasan buatan yang telah didefenisikan oleh beberapa ahli. T.Sutojo, Edy Mulyono, V.Suhartono (2011).

\subsection{Sistem Pakar}

Sistem pakar (expert system) adalah sistem yang berusaha mengadopsi pengetahuan manusia ke komputer, agar komputer dapat menyelesaikan masalah seperti yang biasa dilakukan oleh para ahli. Sistem pakar yang baik dirancang agar dapat menyelelasikan suatu permasalahan tertentu dengan meniru kerja dari para ahli. Dengan sistem pakar ini, orang awampun dapat menyelesaikan masalah yang cukup rumit yang sebenarnya hanya dapat diselesaikan dengan bantuan para ahli. Bagi para ahli, sistem pakar ini juga akan membantu aktivitasnya sebagai asisten yang sangat berpengalaman.

Ada beberapa definisi tentang sistem pakar, antara lain :

1. Menurut Durkin Sistem pakar adalah suatu program komputer yang dirancang untuk memodelkan kemampuan penyelesaian masalah yang dilakukan seorang pakar.

2. Menurut Ignizio : Sistem pakar adalah suatu model dan prosedur yang berkaitan, dalam suatu domain tertentu, yang mana tingkat keahliannya dapat dibandingkan dengan keahlian seorang pakar

3. Menurut Giarratano dan Riley : Sistem pakar adalah suatu sistem komputer yang bisa menyamai atau meniru kemampuan seorang pakar.

\subsection{Smartphone}

Smartphone merupakan perangkat pintar dengan kemampuan dan fungsi menyerupai komputer. Smartphone memiliki sistem operasi yang memungkinkannya menjalankan berbagai aplikasi, seperti mengirim dan menerima email, mengedit dokumen, dll. Sistem operasi yang bisa ditemukan di ponsel pintar untuk saat ini adalah Symbian OS, iOS, RIM BlackBerry, Windows Mobile, Linux, Palm, WebOS dan Android.

Di Indonesia, smartphone memilik segmentasi sendiri berdasarkan level harga dan spesifikasinya, yaitu:

1. Smartphone kelas atas (High-End)

Smartphone kelas atas memiliki spesifikasi prosesor, memori, GPU, ukuran layar, jenis layar, dan kamera yang sangat tinggi dengan fitur-fitur unggulan yang menonjol dan lengkap dalam pengoperasiannya. Selain itu, desainnya juga premium dan lebih terkesan bergensi. Dengan semua kelebihan tersebut, 
ponsel pintar kelas atas dihargai cukup mahal mulai dari 4 juta hingga 10 juta rupiah. Beberapa vendor perangkat pintar yang bermain di level ini di antaranya: Apple dengan produk andalannya iPhone, Samsung dengan jajaran seri ponsel cerdas Galaxy S dan Galaxy Note, HTC dengan seri HTC One, LG dengan seri Optimus G dan L9, Nokia dengan seri Lumia 9XX, dan Blackberry dengan seri Qxx.

2. Smartphone kelas menengah (Middle-End) Smartphone kelas menengah membidik pengguna yang menginginkan ponsel pintar dengan harga dan spesifikasi yang lebih rendah. Pasar ponsel cerdas kelas menengah cukup besar, khususnya di Indonesia. Merkmerk smartphone kelas menengah yang populer di Indonesia di antaranya Samsung, Acer, LG, Nokia, Polytron, Lenovo, Asus, Xiaomi, Oppo, dan Blackberry.

3. Smartphone kelas bawah (Low-End) Smartphone kelas bawah juga banyak peminatnya di Indonesia, yang bisa didapatkan dengan harga sangat murah mulai dari 400 ribu rupiah hingga 1 juta an rupiah. Pilihannya pun banyak dengan spesifikasi cukup baik. Smartphone kelas bawah sesuai untuk pengguna pemula yang belum terbiasa dengan ponsel pintar dan ingin mencoba belajar dulu.

Pasar untuk ponsel pintar sangat luas. Hampir semua pengguna ponsel menggunakan smartphone, mulai dari para pengguna profesional hingga sosialita - dari yang muda hingga yang tua - dari yang kaya hingga golongan ekonomi menengah ke bawah. Hal ini karena ponsel cerdas memampukan pengguna untuk membawa, membuat, mengedit dan membagi data kemanapun, dimanapun dan kapanpun. Selain itu, kehadiran smartphone sangat mendukung gaya hidup online (online life style) di era internet ini. Pilihan smartphone yang tersedia juga sangat banyak.

\subsection{Teorema Bayes}

Metode Bayes ini merupakan metode yang baik didalam mesin pembelanjaran berdasarkan data training, dengan menggunakan probabilitas bersyarat sebagai dasarnya. Menurut Sri Hartati dan Sari Iswanti (2008, hal.108) menyatakan bahwa "Probabilitas Bayesian adalah salah satu untuk mengatasi ketidakpastian dengan menggunakan Formula Bayes". Metode Bayes adalah pendekatan secara statistik untuk menghitung Tradeoffs diantara keputusan yang berbeda - beda, dengan menggunakan probabilitas dan costs yang menyertai suatu pengambilan keputusan.

Probabilitas Bayes merupakan salah satu cara untuk mengatasi ketidakpastian data dengan cara menggunakan formula bayes yang dinyatakan dengan:

Bentuk teorema bayes untuk evidence tunggal dan hipotesis tunggal $\mathrm{H}$ adalah :

$$
p(H \mid E)=\frac{p(E \mid H) * p(H)}{p(E)}
$$

Dimana :

$\mathrm{p}(\mathrm{H} \mid \mathrm{E})$ : probabilitas hipotesis $\mathrm{H}$ terjadi jika evidence E terjadi

$\mathrm{p}(\mathrm{E} \mid \mathrm{H})$ : probabilitas munculnya evidence $\mathrm{E}$, jika hipotesis $\mathrm{H}$ terjadi

$\mathrm{p}(\mathrm{H})$ : probabilitas hipotesis $\mathrm{H}$ tanpa memandang evidednce apapun

$\mathrm{p}(\mathrm{E})$ : probabilitas evidence $\mathrm{E}$ tanpa memandang apapun.

Bentuk teorema bayes untuk evidence tunggal E dan hipotesis ganda $\mathrm{H} 1, \mathrm{H} 2, \ldots, \mathrm{Hn}$ adalah :

$$
\mathrm{p}(\mathrm{Hi} \mid \mathrm{E})=\frac{\mathrm{p}(\mathrm{E} \mid \mathrm{Hi}) * \mathrm{p}(\mathrm{Hi})}{\sum_{\mathrm{k}=1}^{\mathrm{n}} \mathrm{p}(\mathrm{E} \mid \mathrm{Hi}) * \mathrm{p}(\mathrm{Hi})}
$$


Dimana :

$\mathrm{p}(\mathrm{Hi} \mid \mathrm{E})$ : probabilitas hipotesis $\mathrm{Hi}$ terjadi jika evidence E terjadi

$\mathrm{p}(\mathrm{E} \mid \mathrm{Hi})$ : probabilitas munculnya evidence $\mathrm{E}$, jika hipotesis Hi terjadi

p(Hi) : probabilitas hipotesis Hi tanpa memandang evidednce apapun

n : Jumlah Hipotesis yang terjadi

Untuk evidence ganda E1, E2, ...., Em dan hipotesis ganda $\mathrm{H} 1, \mathrm{H} 2, \ldots . \mathrm{Hn}$ adalah:

$$
\begin{aligned}
& \mathrm{p}(\mathrm{Hi} \mid \mathrm{E} 1 \mathrm{E} 2 \ldots . \mathrm{Em}) \\
& =\frac{\mathrm{p}(\mathrm{E} 1 \mathrm{E} 2 \ldots . \mathrm{Em} \mid \mathrm{Hi}) * \mathrm{p}(\mathrm{Hi})}{\sum_{\mathrm{k}=1}^{\mathrm{n}} \mathrm{p}(\mathrm{E} 1 \mathrm{E} 2 \ldots . \mathrm{Em} \mid \mathrm{Hi}) * \mathrm{p}(\mathrm{Hk})}
\end{aligned}
$$

\section{PEMBAHASAN DAN HASIL}

\subsection{Pembahasan}

Pada bagian ini diberikan contoh proses akuisisi dan representasi pengetahuan suatu perangkat, dalam hal ini akan diambil contoh prediksi penjualan smartphone di kota metro lampung dengan faktor- faktor sebagai berikut:

1. Mayoritas kelas sosial di kota metro masih menegah ke bawah

2. UMK kota metro tahun 2018 adalah Rp 2.075 .000

3. Penduduk kota metro terdiri dari laki-laki dan perempuan

4. Jumlah penduduk kota metro 152.428 jiwa ( kota kecil )

Penyelesaaian :

1. Identifikasi jenis jenis Smartphone

Adapun untuk menentukan segementasi pasar Smartphone perlu diketahuia bahwa ada 3 pengelompokan berdasarkan level harga dan spesifikasi antara lain sebagai berikut :
Tabel 3.1 Jenis Smartphone

\begin{tabular}{|l|l|l|}
\hline No. & $\begin{array}{c}|c| \\
\text { Kode } \\
\text { Smartphone }\end{array}$ & \multicolumn{1}{|c|}{ Nama Smartphone } \\
\hline 1 & S01 & $\begin{array}{l}\text { Smartphone Low-End } \\
\text { (Kelas Bawah) }\end{array}$ \\
\hline 2 & S02 & $\begin{array}{l}\text { Smartphone Midle-End } \\
\text { (Kelas Menengah) }\end{array}$ \\
\hline 3 & S03 & $\begin{array}{l}\text { Smartphone High-End } \\
\text { (Kelas Atas) }\end{array}$ \\
\hline
\end{tabular}

2. Identifikasi Faktor Segmentasi Pasar Smartphone

Berdasarkan 3 jenis smartphone tersebut maka diperoleh 20 faktor penentu berdasarkan geografi bisnis dan demografi. Adapun kode faktor dari jenis smartphone antara lain :

\begin{tabular}{|c|c|c|}
\hline No. & Kd. Faktor & Nama Faktor \\
\hline 1 & F01 & $\begin{array}{l}\text { Kelas menengah lapisan } \\
\text { keatas ( upper midle class) }\end{array}$ \\
\hline 2 & F02 & $\begin{array}{l}\text { Kelas menengah lapisan } \\
\text { kebawah ( lower midle } \\
\text { class) }\end{array}$ \\
\hline 3 & F03 & Usia $<17$ tahun \\
\hline 4 & F04 & Usia $17-25$ tahun \\
\hline 5 & F05 & Usia 25-45 tahun \\
\hline 6 & F06 & Usia $>45$ tahun \\
\hline 7 & F07 & $\begin{array}{l}\text { UMR/UMK/UMP } \\
<1.500 .000\end{array}$ \\
\hline 8 & F08 & $\begin{array}{l}\text { UMR/UMK/UMP } \\
1.600 .000-2.900 .000\end{array}$ \\
\hline 9 & F09 & $\begin{array}{l}\text { UMR/UMK/UMP } \\
>3.000 .000\end{array}$ \\
\hline 10 & F10 & Laki-laki \\
\hline 11 & F11 & Perempuan \\
\hline 12 & F12 & Pekerjaan ( PNS ) \\
\hline 13 & F13 & $\begin{array}{l}\text { Pekerjaan ( Karyawan } \\
\text { swasta ) }\end{array}$ \\
\hline 14 & F14 & Pekerjaan (wirausaha) \\
\hline 15 & F15 & Pekerjaan (mahasiswa ) \\
\hline 16 & F16 & Pekerjaan (pelajar ) \\
\hline 17 & F17 & Kota kecil (100.000 jiwa) \\
\hline 18 & F18 & $\begin{array}{l}\text { Kota Sedang } \\
(500.000 \text { jiwa })\end{array}$ \\
\hline 19 & F19 & $\begin{array}{l}\text { Kota Besar } \\
(500.000-1.000 .000 \text { jiwa })\end{array}$ \\
\hline
\end{tabular}

Tabel 3.2 Pengkodean Faktor 


\begin{tabular}{|l|l|l|}
\hline 20 & F20 & $\begin{array}{c}\text { Kota Metropolitan } \\
(>1.000 .000 \text { jiwa })\end{array}$ \\
\hline
\end{tabular}

3. Buat Hipotesis Awal

Hipotesis H1 adalah Smartphone Low-End (Kelas Bawah)

Hipotesis H2 adalah Smartphone Midle-End (Kelas Menengah)

Hipotesis H3 adalah Smartphone High-End (Kelas Atas)

4. Lakukan masing-masing perhitungan tingkat keprcayaan prediksi segementasi pasar menggunakan Teorema Bayes.

a. Pertama kita buat tabel hasil survei penjualan smartphone berdasarkan riwayat data penjualan di Toko Pasadena Cellular Bandar Lampung.

Tabel 3.3 Survey Penjualan Smartphone

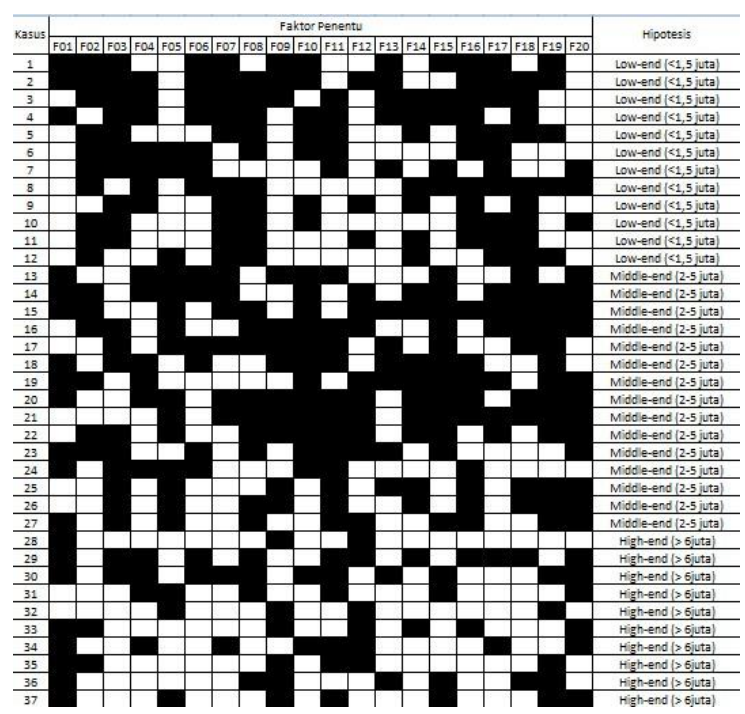

5. Hitung probabilitas setiap hipotesis tanpa memandang gejala (evidence) apapun, maka probabilitas adalah:

$$
\begin{aligned}
& \mathrm{H} 1=\frac{12}{37}=0,324 \\
& \mathrm{H} 2=\frac{15}{37}=0,405 \\
& \mathrm{H} 3=\frac{10}{37}=0,27
\end{aligned}
$$

6. Hitung Probabilitas setiap gejala (evidence E) untuk setiap hipotesis. Sehingga diperoleh probabilitas setiap gejala, yaitu :

Tabel 3.4 Probabilitas gejala untuk setiap hipotesis

\begin{tabular}{|l|l|l|}
\hline Smartphone Low-end & Smartphone Middle-end & Smartphone High-end \\
\hline $\mathrm{P}(\mathrm{E} 02 \mid \mathrm{H} 1)=3 / 12=0,25$ & $\mathrm{P}(\mathrm{E} 02 \mid \mathrm{H} 2)=6 / 15=0,4$ & $\mathrm{P}(\mathrm{E} 02 \mid \mathrm{H} 3)=2 / 10=0,2$ \\
\hline $\mathrm{P}(\mathrm{E} 08 \mid \mathrm{H} 1)=10 / 12=0,83$ & $\mathrm{P}(\mathrm{E} 08 \mid \mathrm{H} 2)=9 / 15=0,6$ & $\mathrm{P}(\mathrm{E} 08 \mid \mathrm{H} 3)=4 / 10=0,4$ \\
\hline $\mathrm{P}(\mathrm{E} 10 \mid \mathrm{H} 1)=7 / 12=0,58$ & $\mathrm{P}(\mathrm{E} 10 \mid \mathrm{H} 2)=12 / 15=0,8$ & $\mathrm{P}(\mathrm{E} 10 \mid \mathrm{H} 3)=2 / 10=0,2$ \\
\hline $\mathrm{P}(\mathrm{E} 11 \mid \mathrm{H} 1)=5 / 12=0,42$ & $\mathrm{P}(\mathrm{E} 11 \mid \mathrm{H} 2)=12 / 15=0,8$ & $\mathrm{P}(\mathrm{E} 11 \mid \mathrm{H} 3)=6 / 10=0,6$ \\
\hline $\mathrm{P}(\mathrm{E} 17 \mid \mathrm{H} 1)=10 / 12=0,83$ & $\mathrm{P}(\mathrm{E} 17 \mid \mathrm{H} 2)=6 / 15=0,4$ & $\mathrm{P}(\mathrm{E} 17 \mid \mathrm{H} 3)=2 / 10=0,2$ \\
\hline
\end{tabular}

7. Hitung probablitas untuk setiap Hipotesis berdasarkan evidence E02 E08 E10 E11 E17 dengan persamaan :

a. Untuk probabilitas hipotesis berdasarkan evidence E02 E08 E10 E11 E17 adalah :

\section{P = (H1 $\mid$ E02 E08 E10 E11 E17)}

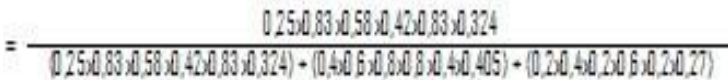

$$
\begin{aligned}
& =\frac{0,013593099}{0,0389996999}=0,349588
\end{aligned}
$$

b. Untuk probabilitas hipotesis berdasarkan evidence E02 E08 E10 E11 E17 adalah :

$\mathrm{P}=(\mathrm{H} 2 \mid \mathrm{E02}$ E08 E10 E11 E17)

$0,40,8,0,8 \times 0,8,0,40,405$

$0250,83,058,0,420,83,0,324) *(0,40,6,0,808,8,0,40,405) *(0,30,40,306,60,20,27)$

$$
=\frac{0,0248832}{0,0389994699}=0,063818
$$

c. Untuk probabilitas hipotesis berdasarkan evidence E02 E08 E10 E11 E17 adalah :

P = (H3| E02 E08 E10 E11 E17)

$030,402006,307$

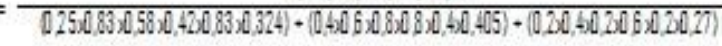

$=\frac{0,000584}{0,038994699}=0,033294$ 


\section{KESIMPULAN DAN SARAN}

\subsection{Kesimpulan}

Setelah melakukan berbagai tahapan bayes pada studi kasus segementasi pasar smartphone di kota metro lampung, tampak bahwa setelah Evidence E02, E08, E10, E11, E17 teramati, tingkat kepercayaan pada hipotesis $\mathrm{H} 2$ lebih besar dari pada hipotesis $\mathrm{H} 1$ dan $\mathrm{H} 3$ dengan nilai keprcayaan 0,6381118

\subsection{Saran}

Berdasarkan kesimpulan diatas, peneliti menyarankan untuk segementasi pasar penjualan smartphone dikota metro adalah Smartphone Midle-End (Kelas Menengah) dengan harga yang masih terjangkau namun memiliki spesifikasi tinggi

\section{DAFTAR PUSTAKA}

Sutojo, T. dan Edy Mulyanto, Vincent Suhartono 2010. KECERDASAN BUATAN. Yogyakarta : ANDI Yogyakarta.

Kotler \& Keller. 2009. Manajemen Pemasaran, Edisi Milenium, Jilid I. Jakarta. PT. Erlangga.
Malhotra, N. K. 2005. Riset Pemasaran, Pendekatan Terapan. Edisi keempat. Jilid 2. PT. Indeks Kelompok Gramedia. Jakarta

Kasali, R. (2007). Membidik Pasar Indonesia: Segementasi, Targeting, Positioning. Jakarta: Gramedia Pusaka Utama.

Julianda, Ikko dan Eka Komalasari. 2017. Faktor Yang Memperngaruhi Konsumen Dalam Pembelian Produk Smartphone Samsung. Riau : Universitas Islam Riau.

Upoyo, Gangsar. 2018. Faktor Yang Memperngaruhi Konsumen Membeli Smartphone Oppo. Yogyakarta : Universitas Sanata Dharma.

Nuriyanti, Widya. 2017. Segementasi Pasar Berdasarkan Demografi Dalam Memilih Sepeda motor Matic Di Wilayah Depok. Jakarta Timur : Universitas Indraprasta PGRI. 